\title{
Perancangan Alat Ukur Kelembaban Tanah Media Tanaman Hias Menggunakan Sensor YL-69 Berbasis Arduino Uno
}

\author{
Andriansyah Murasyd', M. Rizky Azhari², Amar Abdullah ${ }^{3}$, Sri Muryani ${ }^{4}$ \\ 1,2,3,4 Teknik Informatika, Universitas Nusa Mandiri \\ 1e-mail: andreemrsyd@gmail.com \\ 2e-mail: muhammadrizky141296@gmail.com \\ 3e-mail: amarabdullah56@gmail.com \\ ${ }^{4}$ e-mail: sri.smy@nusamandiri.ac.id
}

\begin{tabular}{ccc}
\hline Diterima & Direvisi & Disetujui \\
$11-10-2021$ & $30-12-2021$ & $11-01-2022$ \\
\hline
\end{tabular}

\begin{abstract}
Abstrak - Kelembaban tanah adalah air yang memenuhi separuh atau seluruh pori-pori tanah yang berada diatas permukaan air tanah. Pengertian kelembaban tanah yang lain menyatakan bahwa jumlah air yang tersimpan diantara pori-pori tanah sangat dinamis, hal ini dikarenakan oleh penguapan melalui permukaan tanah. Kegunaan kelembaban tanah adalah untuk manajemen sumber daya air, peringatan dini kekeringan dan perencanaan irigasi. Kurangnya air dalam kelembaban tanah dapat menyebabkan kelayunan pada tanaman dan tindakan perbaikan dengan melakukan penyiraman/irigasi yang tepat pada waktunya dapat menyelamatkan tanaman. Tanaman hias adalah tanaman yang di pelihara karena nilai keindahan pada bunganya. Tanaman yang mempunyai nilai keindahan baik bentuk, warna daun maupun bunganya, sering digunakan untuk penghias rumah, pekarangan dan lain sebagainya. Dilansir dari republika.co.id, selama pandemi Covid-19 pembeli yaitu para pecinta tanaman datang membeli beragam tanaman hias, omzet penjual meningkat tajam bisa mencapai rata-rata 300 persen dari biasanya. Contoh tanaman hias yang cocok ditanam di tanah yang kering adalah kaktus, tanah yang lembab adalah tanaman suplir, sedangkan tanah yang basah adalah sirih gading. Apabila suhu tanah menunjukan suhu $0^{\circ}-40^{\circ} \mathrm{C}$ maka nilai kelembaban tanah kering, suhu $40^{\circ}-70^{\circ} \mathrm{C}$ menunjukan nilai kelembaban tanah lembab, dan suhu $70^{\circ}-100^{\circ} \mathrm{C}$ menunjukan nilai kelembaban tanah basah. Berdasarkan uraian tersebut, maka dibuat penelitian dengan tema perancangan alat ukur kelembaban tanah pada tanaman hias menggunakan sensor YL-69 berbasis arduino uno. Dalam penelitian ini komponen utama yang digunakan adalah mikrokontroler Arduino Uno, NodeMCU, LCD serta Soil Moisture Sensor YL-69. Alat ini juga akan terhubung pada Smartphone melalui wi-fi menggunakan aplikasi Blynk yang akan menampilkan informasi mengenai nilai suhu kelembaban tanah yang diukur. Tujuan dari pembuatan alat ini adalah untuk mempermudah dalam memantau dan mengontrol suhu kelembaban tanah serta membedakan tingkatan suhu tanah yang kering atau basah.
\end{abstract}

Kata Kunci: Kelembaban Tanah, Arduino Uno, NodeMCU, YL-69, LCD

Abstract - Soil moisture is water that fills half or all of the soil pores above the ground water surface. Another definition of soil moisture states that the amount of water stored between soil pores is very dynamic, this is due to evaporation through the soil surface. Soil moisture is used for water resource management, drought early warning and irrigation planning. Lack of water in soil moisture can cause wilting in plants and corrective action by doing watering/irrigation in a timely manner can save plants. Decorative plants are plants that are maintained because of the beauty value in their flowers. Plants that have a beauty value in terms of shape, color of leaves and flowers, are often used to decorate homes, yards and so on. Reporting from Republika.co.id, during the Covid-19 pandemic, buyers, namely plant lovers, came to buy various decorative plants, the sales turnover increased sharply, reaching an average of 300 percent from usual. Examples of decorative plants that are suitable for planting in dry soil are cacti, moist soil is suplir plants, while wet soil is ivory betel. If the soil temperature shows a temperature of $0^{\circ}-40^{\circ} \mathrm{C}$ then the value of dry soil moisture, a temperature of $40^{\circ}-70^{\circ} \mathrm{C}$ indicates the value of moist soil moisture, and a temperature of $70^{\circ}-100^{\circ} \mathrm{C}$ indicates the value of wet soil moisture. Based on this description, a research was made with the theme of designing a soil moisture meter for decorative plants using an Arduino Uno-based YL-69 sensor. In this study, the main components used are Arduino Uno microcontroller, NodeMCU, LCD and YL-69 Soil Moisture Sensor. This tool will also be 
connected to the Smartphone via wi-fi using the Blynk application which will display information about the measured soil moisture temperature value. The purpose of making this tool is to make it easier to monitor and control the temperature of soil moisture and distinguish between dry and wet soil temperature levels.

Keywords: Soil Moisture, Arduino Uno, NodeMCU, YL-69, LCD

\section{PENDAHULUAN}

Salah satu media tanam untuk tanaman ialah tanah, baik tanaman hias ataupun tanaman pertanian yang sangat berguna bagi manusia dan makhluk hidup lainnya. Iklim (suhu dan curah hujan), bentuk wilayah (bentuk permukaan tanah), bahan induk, waktu dan organisme mampu membuat sifat tanah yang dinamis itu terus menerus mengalami perubahan (I. W. Suastika, 2014).

Kelembaban tanah adalah air yang memenuhi separuh atau semua pori-pori tanah yang berada diatas permukaan air tanah. Pengertian kelembaban tanah yang lain menjelaskan bahwa jumlah air yang tersimpan diantara pori-pori tanah sangat dinamis, hal ini dikarenakan oleh penguapan melalui permukaan tanah (A. Galih Mardika, 2019) .

Kualitas kelembaban tanah yang melebihi batas bisa memicu permasalahan dan keadaan tanah yang terlalu lembab saat melakukan kegiatan permanen hasil pertanian yang menggunakan alat-alat mekanik dapat mengakibatkan kesulitan (J. Desember, 2017). Suhu kelembaban tanah juga penting diketahui oleh manusia dalam menggunakan sumber-sumber tanah, suhu tanah juga bisa berdampak pada penyerapan air. Kekurangan air pada kelembaban tanah bisa mengakibatkan tanaman menjadi layu dan tindakan pencegahan yang baik dan benar dengan melakukan penyiraman/irigasi dapat menyelamatkan tanaman dari kelayuan (H. Karamina, 2018).

Tanaman hias adalah tanaman yang dipelihara karena nilai kecantikan pada bunganya. Tanaman yang mempunyai nilai kecantikan baik bentuk, warna daun, bunga serta tajuknya, biasa berfungsi sebagai penghias rumah, pekarangan dan lain sebagainya. Dilansir dari republika.co.id, selama pandemi Covid-19 pembeli yaitu para pecinta tanaman datang membeli beragam tanaman hias, omzet penjual meningkat tajam bisa mencapai ratarata 300 persen dari biasanya ( D. Purnomo, 2017).

Contoh tanaman hias yang cocok ditanam di tanah yang kering adalah kaktus, tanah yang lembab adalah tanaman suplir, sedangkan tanah yang basah adalah sirih gading.

Atas hal tersebut diatas maka dibutuhkan suatu alat yang mampu memonitoring suhu kelembaban tanah agar tanaman terpelihara dengan baik, Apabila suhu tanah menunjukan suhu $0^{\circ}-40^{\circ} \mathrm{C}$ maka nilai kelembaban tanah kering, suhu $40^{\circ}-70^{\circ} \mathrm{C}$ menunjukan nilai kelembaban tanah lembab, dan suhu $70^{\circ}-100^{\circ} \mathrm{C}$ menunjukan nilai kelembaban tanah basah. Alat ini nantinya dilengkapi dengan sensor soil moisture Y1-69 dan LCD 2 x 16, yang kemudian akan bekerja untuk menampilkan suhu kelembaban tanah, dalam pembuatan alat ini juga menggunakan mikrokontroler Arduino Uno. Dengan adanya alat ini diharapkan dapat mengurangi resiko kegagalan juga bisa meringankan pekerjaan manusia dalam proses pemeliharaan tanaman dan diharapkan juga dapat mengontrol keadaan tanaman itu sendiri.

\section{METODOLOGI PENELITIAN}

\section{Konsep Dasar Model Pengembangan Sistem}

Prototipe adalah bentuk dasar atau model awal dari peningkatan suatu program atau perangkat lunak. Prototipe biasanya dibangun menjadi model bertujuan untuk memperlihatkan konsep-konsep atau sebagai elemen dari proses peingkatan atau pembuatan sebuah software/alat.

Tujuan menggunakan metode prototyping di dalam penelitian adalah agar peneliti memperoleh gambaran yang ingin dibuat berupa aplikasi dengan diawali tahap penyusunan aplikasi prototype yang akan dipertimbangkan oleh pemakai. Aplikasi prototype yang telah dipertimbangkan oleh user kemudian akan digunakan contoh untuk membuat ciptaan akhir suatu alat yang dijadikan sebagai output dari penelitian ini.

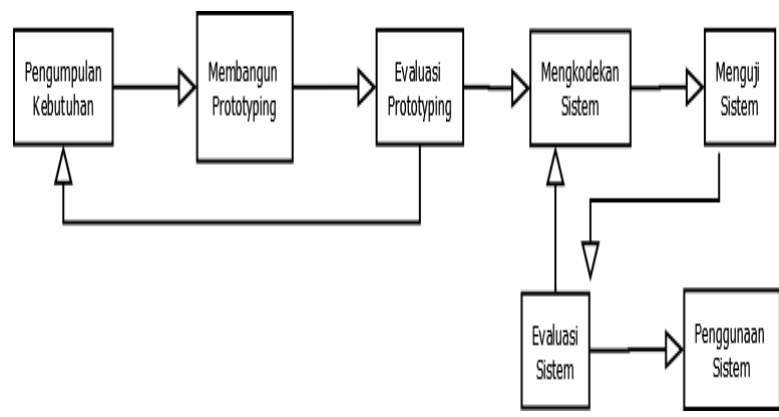

Sumber : Purnomo (2017)

Gambar 1. Langkah-Langkah Prototyping

\section{Konsep Dasar Program}

Menurut Kadir dalam (Fadallah \& Rosyida (2018), "Program adalah kumpulan instruksi yang digunakan untuk mengatur komputer agar melakukan suatu tindakan tertentu'.

Dari definisi program tersebut bisa definisikan bahwa program adalah kumpulan perintah atau instruksi yang ditulis menggunakan bahasa pemrograman tertentu dalam bentuk kode-kode yang digunakan untuk mengatur komputer dengan maksud untuk melakukan suatu tindakan yang diinginkan oleh pengguna.

Dalam penelitian ini menggunakan peralatan pendukung berupa Arduino Uno, NodeMcu, Blue LCD, Soil Moisture Sensor, Kabel Jumper, Modul 
I2C, Aplikasi Blynk, Smartphone Android, Jaringan Internet (Wi-Fi).

Perancangan dan pengujian alat ukur kelembaban tanah pada tanaman hias mengunakan sensor yl-69 berbasis arduino dan NodeMCU Esp8266. Perkembangan di bidang teknologi yang semakin modern dan canggih pada masa sekarang ini semiakin mempermudah dalam penggunaan suatu alat, sehingga manusia bisa lebih mudah dalam bekerja karena terciptanya aneka ragam alat bantu yang dibuat dan juga digunakan secara otomatis. Dalam penelitian ini juga membuat suatu program. Gambar berikut adalah kerangka pemikiran untuk tahap-tahap dalam perancangan dalam membuat aplikasi alat ukur kelembaban tanah.

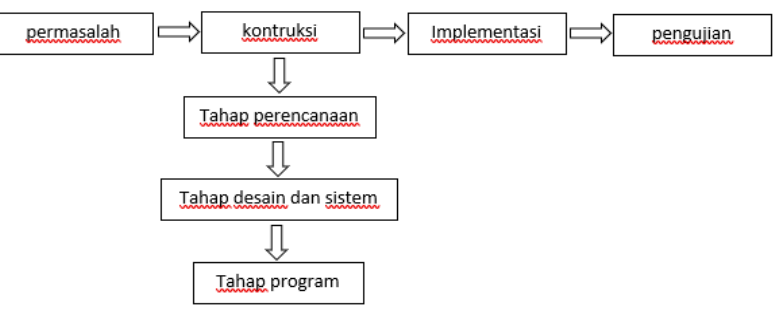

Sumber : Hasil Penelitian (2021)

Gambar 2. Kerangka Pemikiran

Tahap dalam pembuatan suatu program adalah pertama-tama dibuat terlebih dahulu alur kerja sebuah penyusunan alatnya agar lebih terstruktur dalam membuat program dan mengerti program tersebut. Untuk lebih jelasnya bisa dilihat flowchart penyusunan kerja alat pada gambar berikut.

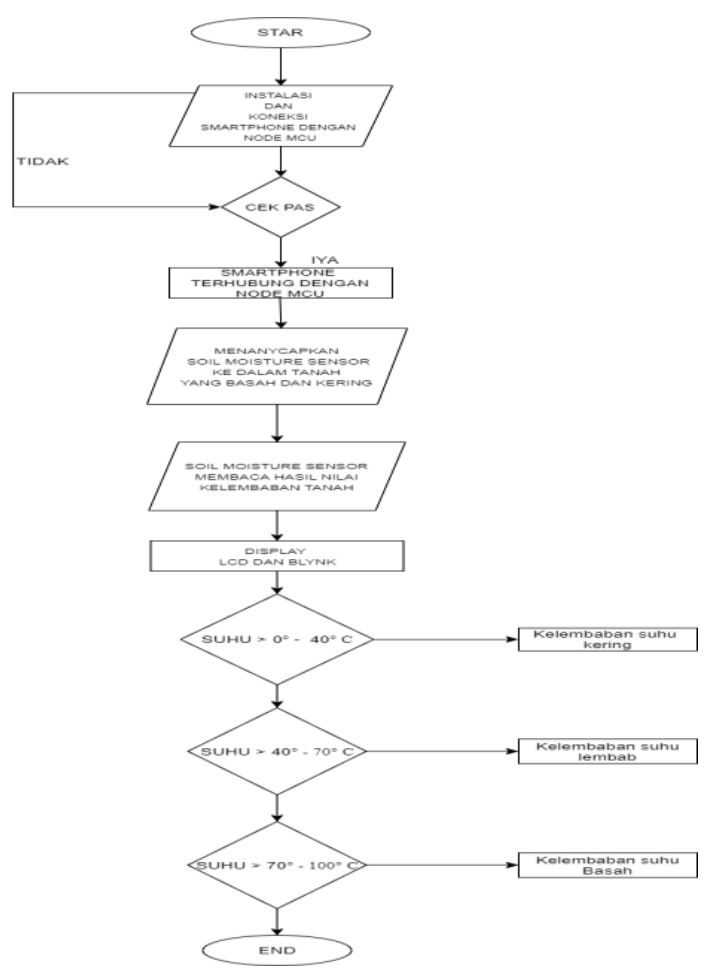

Sumber : Hasil Penelitian (2021)

Gambar 3. Diagram Alat Ukur Kelembaban Tanah pada Tanaman

Keterangan:

1. Start.

2. Instalasi dan menghubungkan smartphone dengan NodeMcu.

3. Cek apakah password sudah benar.

4. Jika berhasil verifikasi password benar perangkat Smartphone yang sudah terinstall aplikasi Blynk terhubung dan masuk ke menu project Blynk yang sudah diatur sebelumnya.

5. Sensor Soil Moisture (YL-69) membaca nilai kelembaban tanah pada tanaman hias.

6. Hasil dari pemrosesan Sensor Soil Moisture (Y1-69) akan di tampilkan di aplikasi Blynk dan dapat dilihat secara langsung di LCD display yang tersedia.

7. Kemudian jika suhu $0^{\circ}-40^{\circ} \mathrm{C}$ menunjukan nilai kelembaban tanah kering, Suhu $40^{\circ}$ $70^{\circ} \mathrm{C}$ menunjukan nilai kelembaban tanah lembab, dan suhu $70^{\circ}-100^{\circ} \mathrm{C}$ menunjukan nilai kelembaban tanah basah.

8. End.

\section{HASIL DAN PEMBAHASAN}

Hasil penelitian dan pembahasan berlandaskan masing-masing variable yang telah ditentukan dalam sebuah uraian lengkap UML (Use Case,Activity Diagram, ERD, Class Diagram, Sequence, Deployment) dan User Interface program/aplikasi yang telah siap diimplementasikan. Use Case

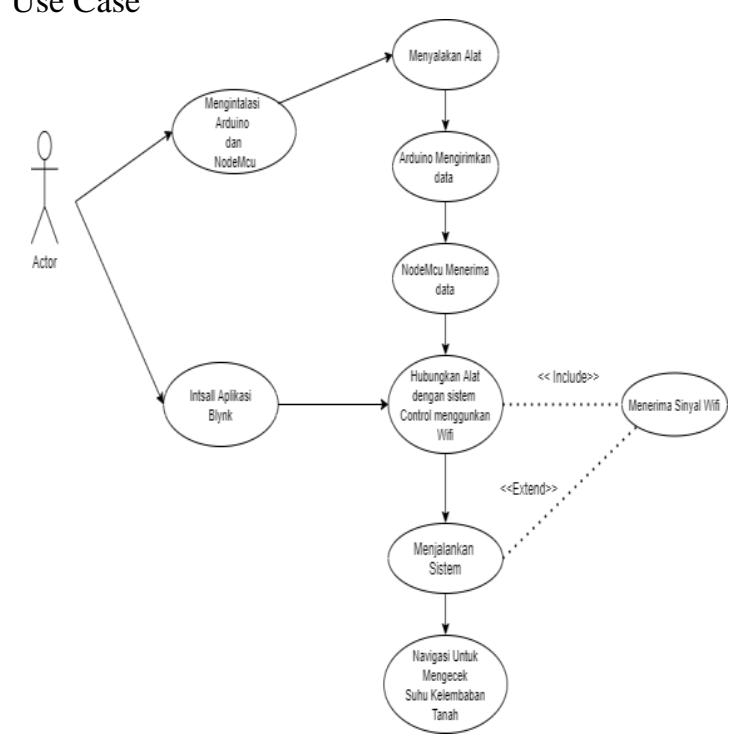

Sumber : Hasil Penelitian, 2021

Gambar 4. Use Case Diagram 
Actor/user dapat menginstalasi Arduino, NodeMcu dan dapat mengecek aplikasi Blynk pada perangkat smartphone yang dihubungkan dengan wireless dengan mengirimkan sinyal ke alat, kemudian jika sudah terhubung maka alat akan menerima sinyal yang dikirimkan oleh aplikasi Blynk. Jika sudah terhubung maka user mengecek dan menjalankan operasi/mengirim sinyal ke NodeMcu, operasi navigasi tersebut untuk di proses sesuai dengan perintah. User mendapatkan hak akses alat selama menerima sinyal dengan system control wi-fi.

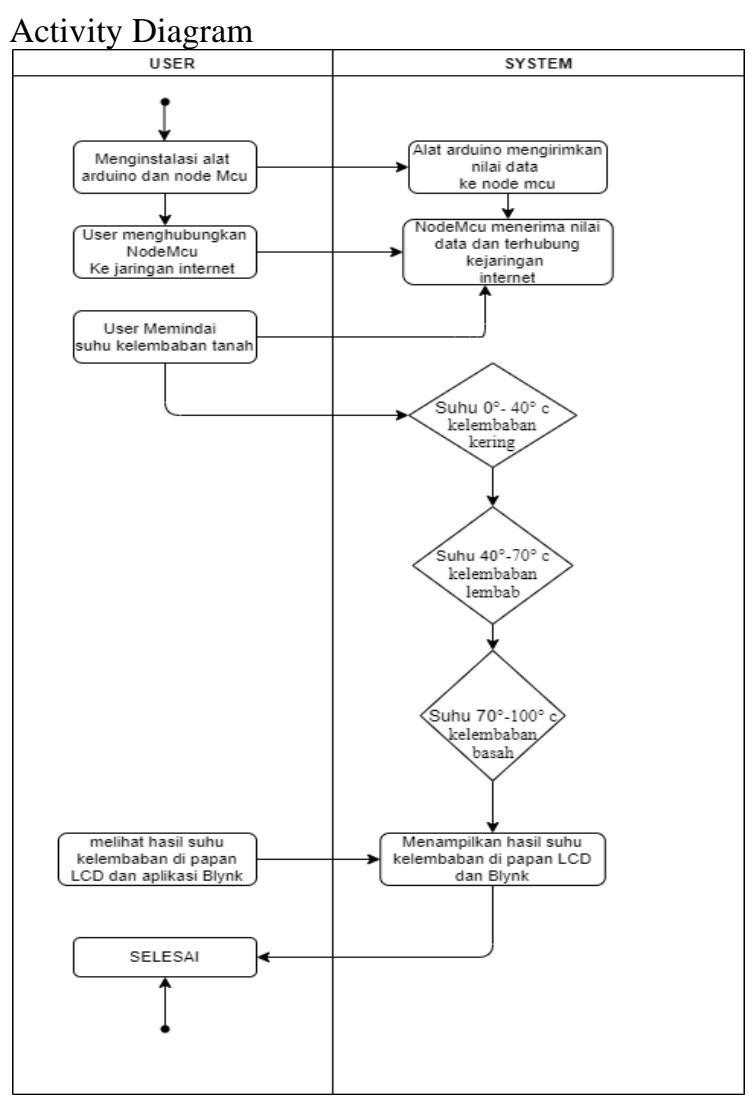

Sumber : Hasil Penelitian, 2021

Gambar 5. Activity Diagram

Perancangan dan Pengujian Alat Ukur Kelembaban Tanah Pada Tanaman Hias menggunakan model Entity Realitionship Diagram (ERD) sebagai model konseptual symbol hubungan yang ada pada sistem monitoring.

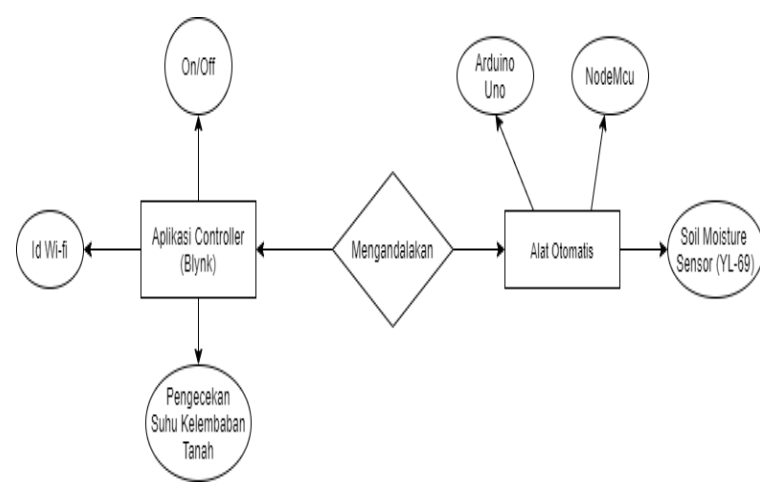

Sumber : Hasil Penelitian 2021

Gambar 6. Entity Relationship Diagram

User Interface

User interface bagian visual dari rancangan alat, software, atau device hardware yang bagaimana seorang actor dapat berinteraksi dengan aplikasi dan rancangan alat serta bagaimana konsep visual tersebut yang ditampilkan pada layer. Tujuan dari actor interface adalah untuk pengguna atau user mudah mengerti dalam segi bentuk apapun apabila tampilan tersebut tidak memiliki actor interface juga.

Dalam Arduino Uno ini sebagai komponen utama pengendali dari rangkaian alat yang menerima instruksi codingan untuk mengirimkan nilai data ke NodeMcu.

NodeMcu juga di letakan bersampingan dengan Arduino, yang akan nantinya akan mengatur Rx dan Tx sebagai penerima data dari arduino dan penghubung ke aplikasi controller (Blynk).

Banyak komponen yang dipakai dalam keseluruhan rancangan alat ukur kelembaban tanah media tanaman hias sehingga nantinya alat tersebut bisa bekerja sesuai instruksi dari pengguna.

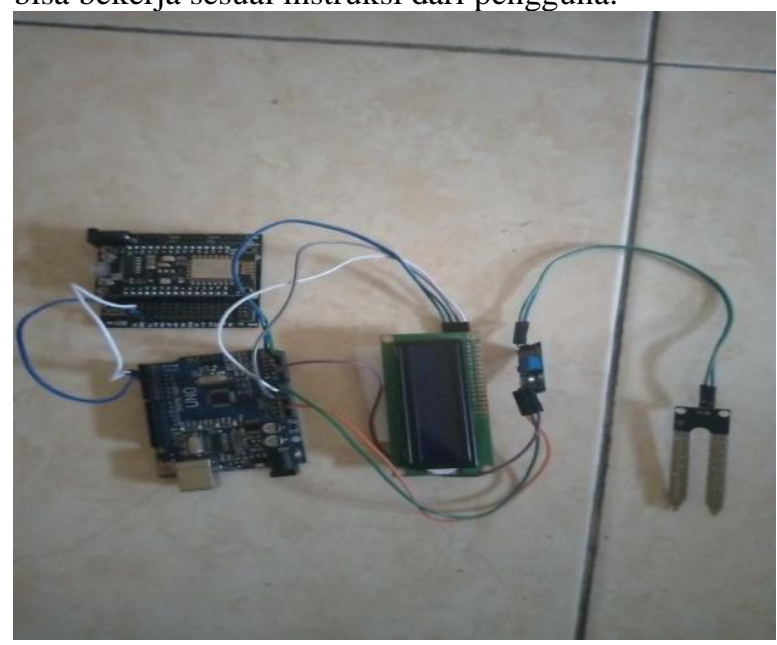

Sumber : Hasil Penelitian 2021

Gambar 7. User Interface Keseluruhan Alat

\section{a. Skema Keseluruhan Rangkaian Alat}

Didalam skematik keseluruhan rangkaian alat ukur kelembaban tanah media tanaman hias memperlihatkan keseluruhan dari prototype 
rancangan. Terdapat beberapa komponen yang terhubung diantarnya adalah board NodeMCU, Arduino Uno, Soil Moisture Sensor (Y1-69) dan LCD 16 X 2.

Arduino Uno Kontroler dari keseluruhan rancangan mengelolah data dan mengirimkan data, Soil Moisture Sensor (YL-69) di gunakan untuk mengetehaui nilai suhu kelembaban. Sebagai jembatan komunikasi antara smartphone dan mikrokontroller menggunakan modul wi-fi yang sudah terpasang di NodeMCU.

Berikut skematik rangkaian keseluruhan mengenai alat ukur kelembaban tanah media tanaman hias yang telah dirancang yaitu:

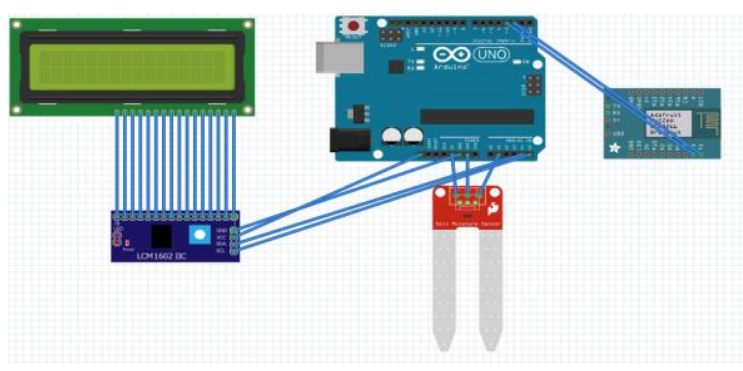

Sumber : Hasil Penelitian, 2021

Gambar 8. Skema keseluruhan

User Interface Aplikasi Controller

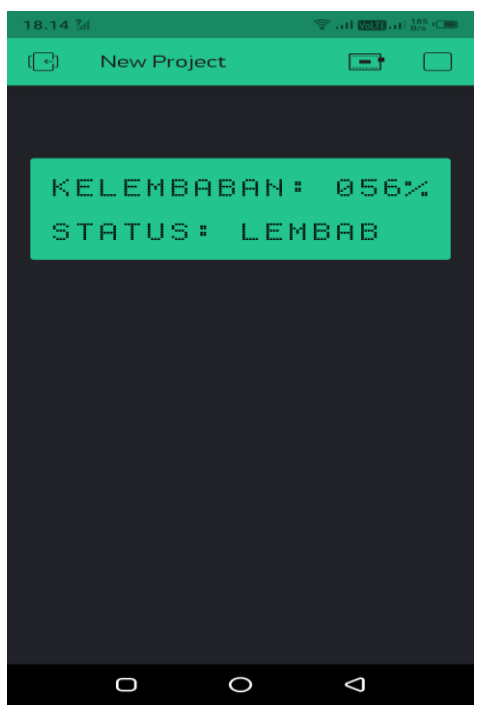

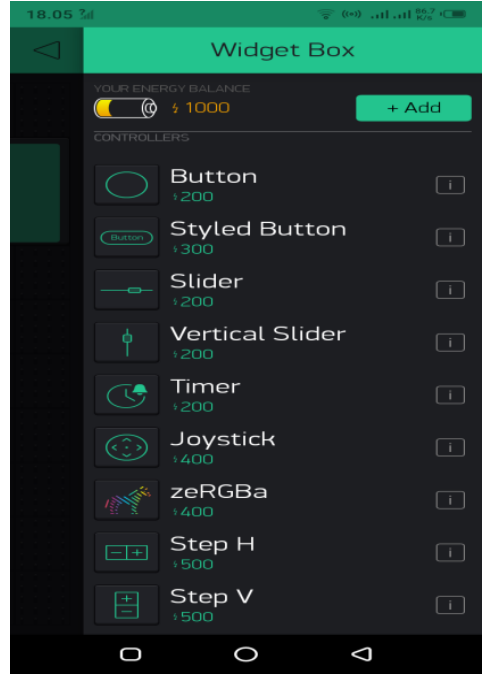

Sumber : Hasil Penelitian 2021

Gambar 9. User Aplikasi Controller

Penjelasan pada Gambar 8 adalah sebelum memakai aplikasi Blynk pastikan smartphone dan NodeMCU sudah terhubung dengan Wi-Fi yang sudah diatur dicodingan NodeMCU. Selanjutnya buka aplikasi Blynk dan membuat project dengan nama kelembaban tanah. Berikut adalah keterangan dari Gambar III. 8:

Keterangan :

1. Button play, bertujuan untuk memulai atau menjalankan project Blynk.

2. LCD, bertujuan untuk memperlihatkan hasil dari suhu kelembaban tanah sebagai media tanaman hias.

3. Button Setting, bertujuan untuk mengatur project yang sudah dibuat.

4. Button Exit, bertujuan untuk keluar dari project Blynk atau kita juga dapat berganti/beralih ke project lain yang ada.

Hasil dari pengujian yang telah dilakukan oleh peneliti dalam pembagian kuisioner di lapangan yang menggunakan tiga skala kepuasan yaitu setuju, cukup dan tidak setuju. Dapat disimpulkan oleh peneliti bahwa perancangan alat ukur kelembaban tanah pada media tanaman hias menggunakan sensor yl-69 berbasis Arduino Uno, dapat diterima dan menyelesaikan masalah yang sering terjadi pada tanaman dengan penjelasan sebagai berikut :

1. Hasil pengujian alat pertanyaan nomor satu terdapat 8 orang memberi jawaban setuju, 1 orang memberi jawaban cukup, dan 1 orang yang memberi jawaban tidak setuju. Dari hasil tersebut menjelaskan setuju bahwa alat yang dibuat oleh peneliti dapat memiliki tampilan aplikasi pada smartphone yang menarik dan mudah dipahami.

2. Hasil pengujian alat pertanyaan nomor dua terdapat 7 orang memberi jawaban setuju, 2 
orang memberi jawaban cukup, dan 1 orang yang memberi jawaban tidak setuju. Dari hasil tersebut menjelaskan setuju bahwa intalasi alat ukur kelembaban suhu tanah pada tanaman mudah dilakukan.

3. Hasil pengujian alat pertanyaan nomor tiga terdapat 6 orang memberi jawaban setuju, 4 orang memberi jawaban cukup, dan tidak ada orang yang memberi jawaban tidak setuju. Dari hasil tersebut menjelaskan setuju bahwa alat yang dibuat oleh peneliti dapat manjadi inovasi alat ukur kelembaban suhu tanah di era informatika.

4. Hasil pengujian alat pertanyaan nomor empat terdapat 9 orang memberi jawaban setuju, 1 orang memberi jawaban cukup, dan tidak orang yang memberi jawaban tidak setuju. Dari hasil tersebut menjelaskan setuju bahwa alat yang dibuat dapat mengatasi masalah kelembaban suhu tanah pada proses pertumbuhan tanaman.

5. Hasil pengujian alat pertanyaan nomor lima terdapat 7 orang memberi jawaban setuju, 3 orang memberi jawaban cukup, dan tidak ada orang yang memberi jawaban tidak setuju. Dari hasil tersebut menjelaskan setuju bahwa pengujian dan pengecekan alat ukur kelembaban tanah pada tanaman terkesan lebih canggih.

6. Hasil pengujian alat pertanyaan nomor enam terdapat 2 orang memberi jawaban setuju, 3 orang memberi jawaban cukup, dan 5 orang yang memberi jawaban tidak setuju. Dari hasil tersebut menjelaskan tidak setuju bahwa alat yang dibuat oleh peneliti masih banyak sekali memiliki kekurangan.

7. Hasil pengujian alat pertanyaan nomor tujuh terdapat 4 orang memberi jawaban setuju, 6 orang memberi jawaban cukup, dan tidak ada orang yang memberi jawaban tidak setuju. Dari hasil tersebut menjelaskan cukup setuju bahwa alat mampu menambah fitur suhu kelembaban pada tanaman agar pertumbuhan terjaga dan tidak layu.

8. Hasil pengujian alat pertanyaan nomor delapan terdapat 7 orang memberi jawaban setuju, 3 orang memberi jawaban cukup, dan tidak ada orang yang memberi jawaban tidak setuju. Dari hasil tersebut menjelaskan setuju bahwa alat yang dibuat masih perlu pengembangan lebih lanjur agar dapat dipasarkan secara luas.

\section{KESIMPULAN}

Kesimpulan diambil dari hasil pembahasan dan pengujian pada alat ukur kelembaban tanah media tanaman hias yang dibuat. Kesimpulan dari hasil penelitian perancangan alat ukur kelembaban tanah pada media tanaman hias menggunakan Sensor Yl69 Berbasis Arduino adalah:

a. Alat ini mampu memonitoring suhu kelembaban tanah yang dicoba melalui aplikasi
Blynk dengan terhubung ke internet dan bisa memperlihatkan nilai suhu dan kelembaban. Nilai $0^{\circ} \mathrm{C}-40^{\circ} \mathrm{C}$ Kelembabannya Kering, Nilai $40^{\circ} \mathrm{C}-70^{\circ} \mathrm{C}$ Kelembabannya Lembab, Nilai $70^{\circ} \mathrm{C}-100^{\circ} \mathrm{C}$ Kelembabannya Basah.

b. Perancangan dan Pengujian Alat Ukur Kelembaban Tanah Pada Tanaman Menggunakan Sensor YL-69 Berbasis Arduino Uno dapat mengetahui kondisi tekstur kelembaban tanah dari beberapa macam tanaman hias.

c. Alat yang telah dirancang dapat berjalan sesuai keinginan, hal ini dapat di buktikan dengan hasil pengujian nilai suhu kelembaban tanah pada aplikasi Blynk untuk mengecek hasil kelembaban menggunakan Sensor YL-69.

\section{REFERENSI}

A. Febtriko, "Jurnal Teknologi dan Sistem Informasi UNIVRAB VOL . 2 No . 1 , Januari 2017 ISSN CETAK : 2477-2062 ISSN ONLINE : 2502-891X SISTEM KONTROL PERTERNAKAN IKAN DENGAN MENGGUNAKAN ISSN CETAK: 24772062 ISSN ONLINE : 2502-891X,” vol. 2, no. 1, hal. 140-149, 2017.

A. Galih Mardika dan R. Kartadie, "Mengatur Kelembaban Tanah Menggunakan Sensor Kelembaban Tanah yl-69 Berbasis Arduino Pada Media Tanam Pohon Gaharu," JOEICT (Jurnal Educ. Inf. Commun. Technol., vol. 03, no. 02, hal. 130-140, 2019.

Daifiria, N. Domloboy, E, dan D. Heryawan, "SISTEM MONITORING KELEMBABAN TANAH DAN SUHU PADA TANAMAN HIAS BERBASIS IOT (INTERNET of THINGS) MENGGUNAKAN RASPBERRY PI," IT J., vol. 7, no. 2, hal. 82-90, 2019, [Daring]. Tersedia pada: http://e-journal.potensi-

utama.ac.id/ojs/index.php/ITJournal/article/v iew/823.

D. Kho, "Pengertian Sensor dan Jenis-Jenis Sensor," teknikelektronika.com, 2020. https://teknikelektronika.com/pengertiansensor-jenis-jenis-sensor/ (diakses Jul 25, 2021).

D. Nusyirwan, A. Guntara, dan P. P. P. Perdana, "Permainan Ular Tangga Berbasis Arduino UNO dan RFID Guna Mengembangkan Ilmu Pengetahuan Anak Sekolah Dasar dalam Mengenal Jenis Tanaman," Rekayasa, vol. 13, no. 1, hal. 88-96, 2020, doi: 10.21107/rekayasa.v13i1.5414

D. Purnomo, "Model Prototyping Pada Pengembangan Sistem Informasi," J I M P J. Inform. Merdeka Pasuruan, vol. 2, no. 2, hal. 54-61, 2017, doi: 
10.37438/jimp.v2i2.67.

H. Karamina, W. Fikrinda, dan A. T. Murti, "Kompleksitas pengaruh temperatur dan kelembaban tanah terhadap nilai $\mathrm{pH}$ tanah di perkebunan jambu biji varietas kristal (Psidium guajava 1.) Bumiaji, Kota Batu," Kultivasi, vol. 16, no. 3, hal. 430-434, 2018, doi: 10.24198/kultivasi.v16i3.13225.

I. W. Suastika, J. Purnomo, dan Y. Supriana, "Pedoman Umum Pengelolaan Tanah dan Hara untuk Pertanian." hal. 51, 2014.

J. Desember dan K. Tanah, "Rancang Bangun Alat Ukur Suhu Tanah, Kelembaban Tanah, dan Resistansi," J. Tek. Elektro, vol. 9, no. 2, hal. 80-86, 2017, doi: 10.15294/jte.v9i2.11087.

M. Sobri Sungkar, "Sistem Keamanan Rumah Berbasis Internet of Things," Smart Comp Jurnalnya Orang Pint. Komput., vol. 9, no. 2, hal. 96-98, 2020, doi: 10.30591/smartcomp.v9i2.1972.
P. Asriya dan M. Yusfi, "Menggunakan Wireless Sensor Berbasis Arduino Uno," J. Fis. Unand, vol. 5, no. 4, hal. 327-333, 2016

R. Sandra, V. Simbar, dan A. Syahrin, "Prototype Sistem Pendeteksi Darah Menggunakan Arduino Uno R3," vol. 8, no. 1, hal. 80-86, 2017.

R. Tullah, Sutarman, dan A. H. Setyawan, "Sistem Penyiraman Tanaman Otomatis Berbasis Mikrokontroler Arduino Uno Pada Toko Tanaman Hias Yopi," J. Sisfotek Glob., vol. 9, no. 1, hal. 100-105, 2019.

Y. Prabowo, H. Widiyantara, dan P. Susanto, "Journal of Control and Network Systems," JCONES J. Control Netw. Syst., vol. 3, no. 2, hal. 9-17, 2014. 